\title{
Rate of processing and judgment of response speed: Comparing the effects of alcohol and practice
}

\author{
E. A. MAYLOR, P. M. A. RABBITT, and S. A. V. CONNOLLY \\ University of Manchester, Manchester, England
}

\begin{abstract}
Both alcohol and practice affect choice reaction time. The present study was conducted to investigate the possibility that impairment from alcohol and improvement with practice could be attributed to changes in the efficiency of control mechanisms (Rabbitt, 1979a), some of which depend upon the ability to judge response speed accurately. Twenty subjects participated in a four-choice reaction time experiment in which they received no alcohol (NA) in Session 1 and either no alcohol (10 subjects) or $0.8 \mathrm{ml}$ alcohol (A) per kilogram of body weight (10 subjects) in Session 2 . The task was to respond as fast and as accurately as possible to each stimulus. In addition, subjects were required to press a fifth key after any response that they considered to be both fast and accurate. Subjects had no difficulty in performing this task: (1) there was a significant difference of $122 \mathrm{msec}$ between the mean response time for correct responses indicated as fast and that for correct responses not indicated as fast, and (2) subjects indicated 1 in 4 correct responses but only 1 in 64 errors. Alcohol increased all response times by approximately $40 \mathrm{msec}$. In contrast, practice decreased response times less for correct responses not indicated as fast than for correct responses indicated as fast. The ability to distinguish between fast and slow responses was thus unaffected by alcohol, but was improved by practice. Responses indicated as "fast" were significantly faster than errors, and appeared to occur without warning (unlike errors, which tended to end a sequence of increasingly fast correct responses). The results suggest that alcohol and practice influence choice reaction time in qualitatively different ways: Alcohol impairs overall response speed but has no effect on the ability to judge response speed, whereas practice im. proves both.
\end{abstract}

Recent models of choice reaction time have emphasized the importance of the ability to monitor the response, both in terms of speed and accuracy. For example, Rabbitt and Vyas (1970) proposed a tracking model for performance of tasks in which the subject is required to respond as fast and as accurately as possible. This instruction implies that "the subject knows precisely how fast he can go without running a risk of making errors" (p. 62). Rabbitt and Vyas suggested that the speed-error tradeoff function, which describes the change in probability that a response will be an error, contingent upon the speed with which it is made, limits the efficiency of performance (see, e.g., Schouten \& Bekker, 1967). The subject has to discover the position of this function to perform optimally. For example, he/she must first make errors by responding too quickly in order to know how fast he/she can respond without making errors. Thus the subject must "track" the response rate to stay within the reaction time region

This research was supported by Grant G8221479 from the Medical Research Council of Great Britain. The authors are grateful to Hermann Mueller for help with computer programming. Requests for reprints should be addressed to Elizabeth Maylor at the Age and Cognitive Performance Research Centre, Oxford Road, Manchester M13 9PL, England. that maximizes speed while maintaining accuracy (Rabbitt, 1979a, 1980).

Rabbitt (1979b) noted that subjects need to know at least three things to control their performance in this way:

(1) They must detect errors when they occur; (2) they must be able to monitor and vary response speed so as to recognise, and avoid, faster (reaction time) bands at which errors are intolerably frequent; (3) they must be able adaptively to control response speeds so as to select optimal (reaction time) bands and avoid others which may be too fast or too slow. (p. 305)

It is well established that performance in choice reaction time tasks is impaired by alcohol (Jennings, Wood, \& Lawrence, 1976) and improved by practice. Depending upon dose, alcohol adversely affects speed (Maylor, Rabbitt, Sahgal, \& Wright, 1987), or accuracy (Wilkinson \& Colquhoun, 1968), or both speed and accuracy (Maylor \& Rabbitt, 1987). With practice, subjects become faster, partly as a result of a change in speed-error tradeoff toward less accurate performance, but also because of a real increase in processing rate (Maylor \& Rabbitt, 1989). The impairment with alcohol and the improvement with practice can be considered in terms of the three aspects of control described by Rabbitt (1979a, 1979b). Preliminary evidence from Maylor and Rabbitt (1987) suggests 
that alcohol does not influence the ability to detect an error and make an immediate characteristic adjustment to the response criterion (see Rabbitt, 1966). There is less evidence relating to the ability to distinguish between a fast and a slow response with and without alcohol and practice.

As Rabbitt (1979b) noted, very fine degrees of temporal discrimination are required in choice reaction time tasks since the range over which speed-error tradeoff operates is only approximately $200 \mathrm{msec}$, for mean reaction times of 500-600 msec with standard deviations of $100-150$ msec (see Maylor \& Rabbitt, 1987). There is evidence from Sanford (1970) that for auditory reaction time, subjects can rate their responses with regard to speed in a meaningful way. An attempt was made to investigate this with alcohol by interrupting subjects in a choice reaction time task and asking them to rate the speed of the last response made with respect to the average speed of the previous block of trials (Maylor et al., 1987). The subjects estimated the speed of their responses with only chance accuracy, whether they had consumed alcohol or not. Also, the information transmitted, as a proportion of the information presented, was low and unaffected by alcohol. However, the number of trials in a session was large compared with the number of interruptions requesting ratings, so that it was suggested that the judgment task may have appeared relatively unimportant. Also the requests for ratings were distracting and the times taken to give ratings were long, with several subjects commenting that, because of the interruption, they had forgotten the speed of their last response.

The present study was an attempt to provide more accurate ratings by requiring the subjects, in effect, to rate every response. They were asked to press a separate key immediately after making any response that they considered to be particularly fast. We adopted an experimental design in which each of two groups participated in two sessions. Both groups received no alcohol in Session 1; in Session 2, one group again received no alcohol (NA/NA) and the other group was given alcohol (NA/A). The advantages of this design include the following: (1) the comparisons of interest are essentially withinsubjects, (2) practice effects are taken into account, and (3) only half the subjects are required to consume alcohol.

\section{METHOD}

\section{Subjects}

Twenty-two subjects (mostly students and technical staff) volunteered in response to advertisements at the University of Manchester. The data from 2 of these subjects were subsequently deleted from the analysis for reasons given in the Procedure. Details of the remaining 20 subjects are given in Table 1. Each subject participated in two 1-h sessions at the same time on consecutive days. Payment on completion of the experiment was $£ 10$.

\section{Apparatus and Stimuli}

The subjects were given alcohol in the form of vodka $(37.5 \%$ alcohol by volume) mixed with pure orange juice and water (see Procedure for exact quantities). A Lion Alcolmeter S-D2
Table 1

Subject Details

\begin{tabular}{|c|c|c|c|c|}
\hline & \multicolumn{4}{|c|}{ Group } \\
\hline & \multicolumn{2}{|c|}{ NA/NA $(N=10)$} & \multicolumn{2}{|c|}{$\mathrm{NA} / \mathrm{A}(N=10)$} \\
\hline & $M$ & $S D$ & $M$ & $S D$ \\
\hline Age (in years) & 22.4 & 3.2 & 22.3 & 2.4 \\
\hline Weight (in kilograms) & 76.4 & 16.8 & 69.7 & 5.8 \\
\hline $\begin{array}{l}\text { Time of Testing } \\
\text { (in hours:minutes) }\end{array}$ & 13:06 & $1: 48$ & $13: 30$ & $2: 12$ \\
\hline
\end{tabular}

Note-NA $=$ no alcohol. $A=$ alcohol.

(Breathalyser) obtained from Lion Laboratories Ltd. (Barry, UK) was used to estimate blood alcohol concentration to the nearest $5 \mathrm{mg}$ alcohol $/ 100 \mathrm{ml}$ blood.

An LSI 11/23 computer with a Cambridge Electronics Design 502 laboratory interface was used to control the experiment and record responses with millisecond accuracy. The stimuli appeared (white on black) in the center of a Hewlett-Packard $1362 \mathrm{XY}$ display monitor with $\mathrm{P}-31$ phosphor. The stimuli were the characters ?, A, B, C, and D, each measuring approximately $7 \times 10 \mathrm{~mm}$. The display program used was the EMDISP system (Shepherd, 1984). The response keys formed part of a keypad, which was placed on the table in front of the subject. There were two keys (unused) on the top row; four keys on the middle row labeled 1, 2, 3, and 4 corresponding to the letters A, B, C, and D (operated by the second and first fingers of the left hand and the first and second fingers of the right hand, respectively); and four keys on the bottom row labeled $5,6,7$, and 8 (key 6 operated by the left thumb). The subject sat approximately $600 \mathrm{~mm}$ from the screen.

\section{Design and Procedure}

Each subject was tested individually and asked not to eat for at least $2 \mathrm{~h}$ before each session and to drink no alcohol on the previous evening. A questionnaire had previously established that there were no excessive drinkers or teetotalers in the sample. In addition, the subject was asked to give details of any current medication or serious illnesses, and to sign a consent form agreeing to take part in the experiment. The subject was warned not to drive, cycle, or handle dangerous machinery for $24 \mathrm{~h}$ and was instructed to inform the experimenter of any side effects experienced as a result of the alcohol.

Session 1 began with the subject's drinking $500 \mathrm{ml}$ in exactly $5 \mathrm{~min}$ (a stopwatch was provided). The drink contained $250 \mathrm{ml}$ pure orange juice, $250 \mathrm{ml}$ water, plus a few drops of vodka that were carefully floated on the top of the drink. The subject was given no information concerning the contents of the drink. After a rest of $5 \mathrm{~min}$, the experiment began. Breath readings were taken as near as possible to 20,35 , and 50 min after the subject finished the drink. The third reading almost always coincided with the completion of the last block of trials; that is, each session lasted just under $1 \mathrm{~h}$.

The procedure for Session 2 was very similar. Again, the subject was given no information about the drink. For 12 of the subjects, the drink was identical to that in Session 1, whereas for the remaining 10 , the drink contained $250 \mathrm{ml}$ pure orange juice, $2.13 \mathrm{ml}$ vodka (i.e., $0.8 \mathrm{ml}$ alcohol) per kilogram body weight, and water (total volume of $500 \mathrm{ml}$ ). The extra 2 subjects in the NA/NA group were included to replace 1 highly inaccurate subject (average error rate in the first session over $15 \%$ ) and 1 exceptionally slow subject (mean response time in Session 1 almost three standard deviations above the mean).

The task was identical in the two sessions. There were 12 blocks of trials with breaks of approximately $30 \mathrm{sec}$ between blocks. There were 302 trials in Block 1, and 202 trials in each of Blocks 2 through 12. The beginning of a block of trials was signaled to the subject by the appearance of "?" in the center of the screen. Blocks 1 to 
11 provided extensive practice at the choice reaction time task; the subject lightly placed the first two fingers of each hand on the keys labeled $1,2,3$, and 4 . When ready to begin, the subject was required to press any one of the keys on the keypad. The screen then went blank for $1 \mathrm{sec}$ before the presentation of the first stimulus (randomly chosen from A, B, C, or D). The subject was required to press the corresponding key as quickly as possible. This immediately removed the stimulus from the screen unless the response was made within the first $100 \mathrm{msec}$ of stimulus presentation. The computer then waited until a "legal" response was made (i.e., more than 100 msec after stimulus onset) before removing the stimulus. Following a delay (the response-stimulus interval, RSI), the next stimulus appeared, which again was randomly chosen but with the restriction that each stimulus was different from the previous one.

For Blocks $1-11$ the instructions were merely to respond to each stimulus as quickly as possible with a single keypress. The subjects were also requested to avoid making more than $10 \%$ errors, that is, a maximum of 30 in Block 1 and 20 in each of Blocks 2 through 12. As indicated earlier, all but 1 of the 22 subjects were able to comply with these instructions.

The RSI for the first block in each session was $300 \mathrm{msec}$. For Blocks 2 to 11 , the RSIs were $50,100,200,400$, and $800 \mathrm{msec}$ (two blocks at each RSI), and the presentation order for these was completely randomized for each subject and for each session. The inclusion of the shorter RSIs ensured that prior to the critical task (Block 12), the subjects received over 2,000 trials of the choice response task in only $40 \mathrm{~min}$.

There were 202 trials in Block 12, with an RSI of $1,000 \mathrm{msec}$. The first 2 trials were for practice only and were therefore not included in the data analysis. In addition to the choice response task, the subjects were instructed to press the key numbered " 6 " (under the left thumb) after any response that they considered to be particularly fast and accurate. No indication was given as to how often they should use this extra key. The subjects were requested to indicate "fast" responses during the RSI (although if key " 6 " was pressed during the first 100 msec of the next stimulus presentation, it was accepted as a rather slow indication that the previous response was "fast").

\section{RESULTS AND DISCUSSION}

As indicated above, the data from 2 subjects were not included in the analysis. Table 1 and the following results and discussion are therefore based on 20 subjects, 10 in each of the two groups (NA/NA and NA/A).

\section{Blood Alcohol Concentration}

The mean levels of alcohol in milligrams per $100 \mathrm{ml}$ of blood estimated from the Breathalyser readings taken 20,35 , and $50 \mathrm{~min}$ after completion of the drink in Session 1 were all zero. They were also zero for the NA/NA subjects in Session 2. The means (and standard deviations) for the NA/A subjects in Session 2 were 63.0 (17.0), 70.5 (21.1), and 69.0 (19.8) after 20,35, and $50 \mathrm{~min}$, respectively. The third reading was always taken either immediately before or after the present task. (The legal limit for driving in England is $80 \mathrm{mg}$ per $100 \mathrm{ml}$ blood. This was exceeded by only 2 of the 10 subjects.)

The results reported in the remaining sections are from Block 12 only (i.e., with the extra key to signal fast and accurate responses).

\section{Overall Error Rates}

The errors were divided into two types: (1) errors caused by pressing the "fast" key in response to the stimulus (i.e., more than $100 \mathrm{msec}$ after its appearance), and (2) errors caused by making an incorrect choice from the four response keys (A, B, C, and D). The numbers of errors were then subjected to an analysis of variance with group (two levels: NA/NA and NA/A) as a betweensubjects factor, and session (two levels: first and second) and error type (two levels as described above) as withinsubjects factors. There were no significant effects of group $[F(1,18)=2.82, p>.1]$ or session $[F(1,18)=2.09$, $p>.1]$, but there was a highly significant effect of error type $[F(1,18)=33.70, p<.01]$. With the exception of an interaction between group and error type that approached significance $[F(1,18)=3.42, p<.08]$, there were no other effects (all remaining $F \mathrm{~s}<1$ ). The results are summarized in Table 2. First, it is clear that most errors are of the second type, that is, an incorrect choice between A, B, C, and D. Second, the group $\times$ error type interaction can be seen as a tendency for the NA/NA group to make more errors of the second type than the NA/A group. However, since there were no interactions involving session, the overall conclusion is that alcohol had no significant effect on error rate.

\section{Numbers of "Fast" Responses}

One subject in the NA/A group failed to indicate any "fast" responses whatsoever in Session 1. He was the slowest of the 20 subjects in terms of his mean correct response time in Session 1, and commented afterward that he felt he required longer than the response-stimulus interval $(1,000 \mathrm{msec})$ to indicate a "fast" response. In Session 2 he indicated six "fast" responses, with a mean time to indicate of $913 \mathrm{msec}$. No other subject had any difficulty in carrying out the task, although several reported that they had erroneously pressed the "fast" key in response to the stimulus.

There were 7,490 correct responses and 510 errors altogether. Of these, 1,947 and 8 responses, respectively, were indicated as "fast." Since the instructions were to indicate fast and accurate responses, these results suggest that subjects were highly efficient at least in terms of the

Table 2

Mean Numbers of Errors (out of 200) Caused by Pressing the "Fast" Key, and Pressing the Incorrect A, B, C, or D Key

\begin{tabular}{ccc}
\multicolumn{4}{c}{ Key, and Pressing the Incorrect A, B, C, or D Key } \\
\hline Group & Session 1 & Session 2 \\
\hline \multicolumn{3}{c}{ Pressing the "Fast" Key } \\
NA/NA & 2.3 & 2.1 \\
NA/A & 2.4 & 3.0
\end{tabular}

Pressing the Incorrect A, B, C, or D Key

\begin{tabular}{lrr} 
NA/NA & 11.9 & 13.2 \\
NA/A & 7.3 & 8.8 \\
\hline
\end{tabular}

Note-NA $=$ no alcohol. $A=$ alcohol. 
latter requirement since they selected a much higher proportion of correct responses (approximately 1 in 4) than error responses (approximately 1 in 64). This is, of course, consistent with previous work demonstrating that in such reaction time experiments, subjects generally know whether or not a response is correct (Rabbitt, 1968).

An analysis of variance was carried out on the numbers of "fast" responses indicated, with group and session as between- and within-subjects factors, respectively. There was no effect of group $(F<1)$ or of session $[F(1,18)=2.65, p>.1]$, and there was no interaction $(F<1)$. Clearly neither alcohol nor practice had any influence on the proportion of responses indicated as "fast." The overall mean number was 49 (out of 200 responses), but there were large individual differences, the numbers ranging from 0 to 176, with a standard deviation of 54 .

\section{Overall Mean Response Times}

The mean response times are summarized in Figure 1. (There were insufficient numbers of errors caused by pressing the "fast" key in response to the stimulus, and errors indicated as "fast," to include in the response time analysis.) Two analyses of variance were initially conducted on the data. The first compared the three types of responses made to the stimulus, namely, correct responses not indicated as "fast" (CF'); correct responses indicated as "fast" (CF); and errors (E) for which the response was $\mathrm{A}, \mathrm{B}, \mathrm{C}$, or $\mathrm{D}$. Group was the betweensubjects factor, and session and response (three levels: $\mathrm{CF}^{\prime}, \mathrm{CF}$, and E) were within-subjects factors. There were no effects of group or session (both $F \mathrm{~s}<1$ ), but there was a highly significant effect of response $[F(2,34)=$ $29.90, p<.01]$. The only significant interaction was that between group and session $[F(1,17)=6.39, p<.05]$. Scheffé tests revealed that $\mathrm{CF}^{\prime}$ responses were significantly slower than $\mathrm{E}$ responses $(F=16.78, p<.01)$, which in turn were slower than CF responses $(F=13.27$, $p<.01)$. The improvement from Session 1 to Session 2 was greater for the NA/NA group ( $25 \mathrm{msec}$ ) than for the NA/A group $(-11 \mathrm{msec})$, leading to the group $\times$ session interaction and indicating an overall alcohol effect of $36 \mathrm{msec}$ (see Figure 2).

The second analysis of variance compared the time to make a "fast" correct response (CF) with the time to indicate it $(\mathrm{CF}+)$. Again, there were three factors: group (between-subjects), session (within-subjects), and response (within-subjects, two levels: $\mathrm{CF}$ and $\mathrm{CF}+$ ). There was no effect of group $(F<1)$, the effect of session approached significance $[F(1,17)=3.80, p<.07]$, and the difference between $\mathrm{CF}$ and $\mathrm{CF}+$ was significant $[F(1,17)=7.71, p<.05]$. There was also an interaction between group and session $[F(1,17)=7.46$, $p<.05]$. Although it appears from Figure 2 that the effect of alcohol was larger for CF+ $(90 \mathrm{msec})$ than for CF (33 msec), the three-way interaction was not significant $[F(1,17)=1.45, p>.1]$.

There are several points to emphasize from these analyses of overall mean response times. First, the influence
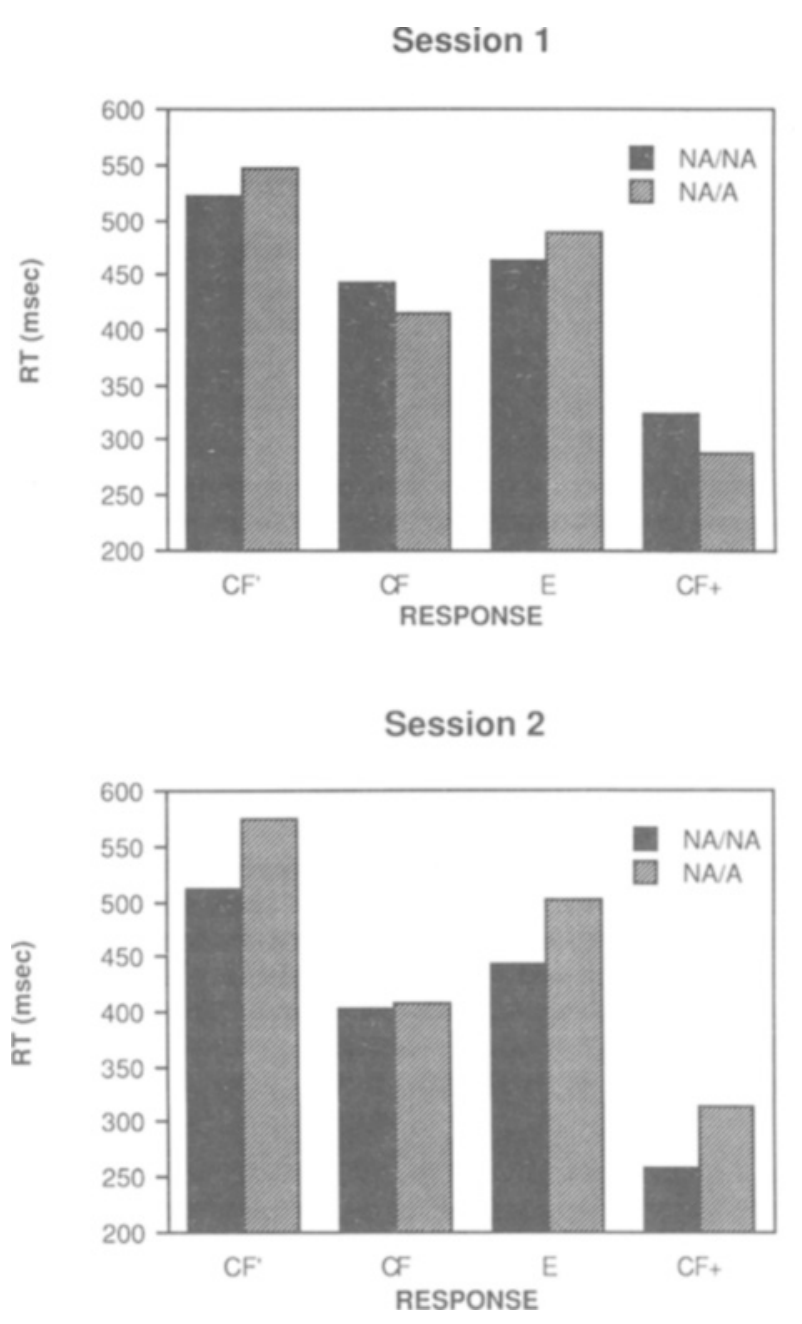

Figure 1. Mean response times for Session 1 and Session 2. $\mathbf{C F}^{\prime}$ $=$ correct responses not indicated as "fast." $\mathrm{CF}=$ correct responses indicated as "fast." $E=$ errors for which the response was $A, B$, $C$, or $D . C F+=$ the time to indicate a "fast" correct response.

of alcohol is clear: responses were slowed by approximately $40 \mathrm{msec}$. Furthermore, the effect was similar for all types of responses, both to the stimulus $\left(\mathrm{CF}^{\prime}, \mathrm{CF}\right.$, and E) and to the response $(\mathrm{CF}+)$. Second, the task was performed well both with and without alcohol in that $\mathrm{CF}^{\prime}$ responses were significantly slower than $C F$ responses (mean difference of $122 \mathrm{msec}$ ). It is perhaps even more surprising that CF responses were even faster (by $57 \mathrm{msec}$ ) than $\mathrm{E}$ responses, which generally occur in such speeded choice tasks before sufficient information has been acquired about the stimulus (see, e.g., Maylor \& Rabbitt, 1987). Third, the time taken to indicate a "fast" response was remarkably short (approximately $300 \mathrm{msec}$ ). Subjects were not instructed to indicate as quickly as possible, but were merely asked to press the "fast" key before the appearance of the next stimulus $(1,000-\mathrm{msec}$ response-stimulus interval). This absence of a speed instruction was probably responsible for the large between- 


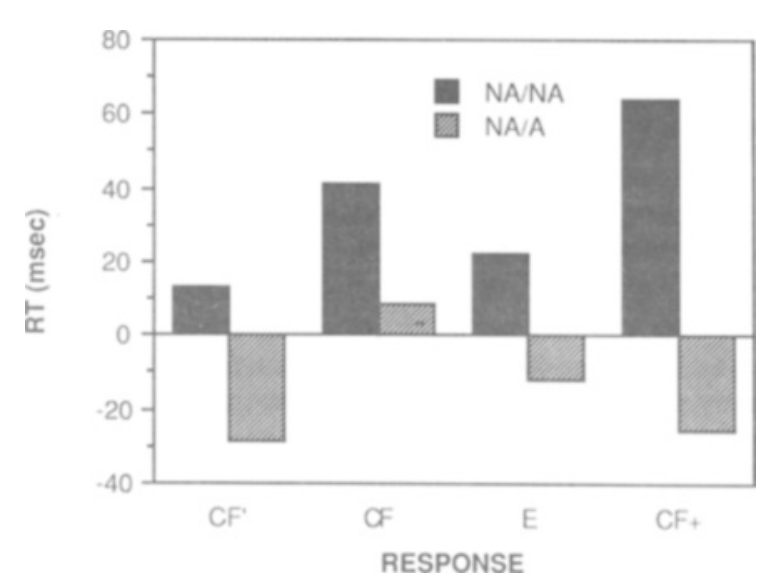

Figure 2. Improvements in mean response times from Session 1 to Session 2. $\mathbf{C F}$ ' = correct responses not indicated as "fast." CF $=$ correct responses indicated as "fast." $E=$ errors for which the response was $A, B, C$, or D. CF $+=$ the time to indicate a "fast" correct response.

subjects variability for $\mathrm{CF}+$ response times compared with those for $\mathrm{CF}^{\prime}, \mathrm{CF}$, and $\mathrm{E}$.

By including $\mathrm{E}$ responses in the first analysis of variance, it seemed that two features of the $\mathrm{CF}^{\prime} / \mathrm{CF}$ data were obscured (the relevant interactions failing to reach significance). The first was that the difference between $\mathrm{CF}^{\prime}$ and CF response times (a measure of how well the subjects were performing the task of distinguishing between fast and slow responses) was larger for the NA/A group than for the NA/NA group (150 and $94 \mathrm{msec}$, respectively). This less-than-perfect matching of groups is of less interest than the second feature, namely that the $\mathrm{CF}^{\prime} / \mathrm{CF}$ difference increased from $106 \mathrm{msec}$ in Session 1 to $138 \mathrm{msec}$ in Session 2. Thus there appears to be evidence that practice actually improves the ability to recognize fast responses. A third analysis of variance was therefore performed on the mean response times for $\mathrm{CF}^{\prime}$ and CF only. The main results were as before: a significant effect of response and an interaction between group and session. However, there was also a significant interaction between session and response $[F(1,17)=7.67$, $p<.05$, and the interaction between group and response approached significance $[F(1,17)=3.71, p<.07]$. Thus there is statistical support for the second of the two suggestions; that is, improvement across sessions was smaller for $\mathrm{CF}^{\prime}$ responses $(-8 \mathrm{msec})$ than for $\mathrm{CF}$ responses (24 msec) (see Figure 2).

\section{What Happens Before and After an Error or a "Fast" Response?}

Several studies have demonstrated that subjects gradually increase their speed in choice response tasks until an error is made; an immediate adjustment then occurs so that the next response is abnormally slow and accurate (Laming, 1968; Maylor \& Rabbitt, 1987; Rabbitt, 1966, 1979a). The question of interest here is whether or not the same pattern applies to correct responses indicated as fast. In other words, do subjects gradually speed up until a particularly fast correct response is made, then immediately become cautious again since to continue at such a speed would involve a high risk of making an error? Also, how are these control mechanisms affected by alcohol and practice?

The first analysis concerned CCECC sequences $(\mathrm{C}=$ correct and $\mathrm{E}=$ error, where the response was $\mathrm{A}, \mathrm{B}, \mathrm{C}$, or $\mathrm{D}$ ) in which each response was not followed by an extra response (e.g., an error correction-see Rabbitt, 1968-or the "fast" key) either during the responsestimulus interval or within $100 \mathrm{msec}$ of the next stimulus presentation. A three-way analysis of variance was conducted on the mean response times with group (betweensubjects), session, and trial type (5 levels: C, C, E, C, and $C$ ) as factors. There were no CCECC sequences for 1 subject in one session, so the results are based on 19 subjects. There was no effect of group $[F(1,17)=1.18$, $p>.1]$ or session $(F<1)$, but there was a highly significant effect of trial type $[F(4,68)=14.29, p<.01]$. The only interaction was between group and session $[F(1,17)=10.38, p<.01]$, with all other $F \mathrm{~s}<1$. Again, the overall improvement from Session 1 to Session 2 was greater for the NA/NA group ( $34 \mathrm{msec}$ ) than for the NA/A group ( $-40 \mathrm{msec})$, indicating an alcohol effect of 74 msec. The trial-type effect is shown in Figure 3.

The general pattern was as expected: a gradual increase in speed until an error occurred (although on Scheffé tests, the difference between the first three trial types did not reach significance), followed by a very slow response. Although there were overall effects on response times of alcohol (an increase from Session 1 to Session 2 for the NA/A group) and of practice (a decrease from Session 1 to Session 2 for the NA/NA group), they did not interact with the CCECC response time sequence. In other words, there was no influence of either alcohol or practice on the control mechanism of detecting and responding to errors.

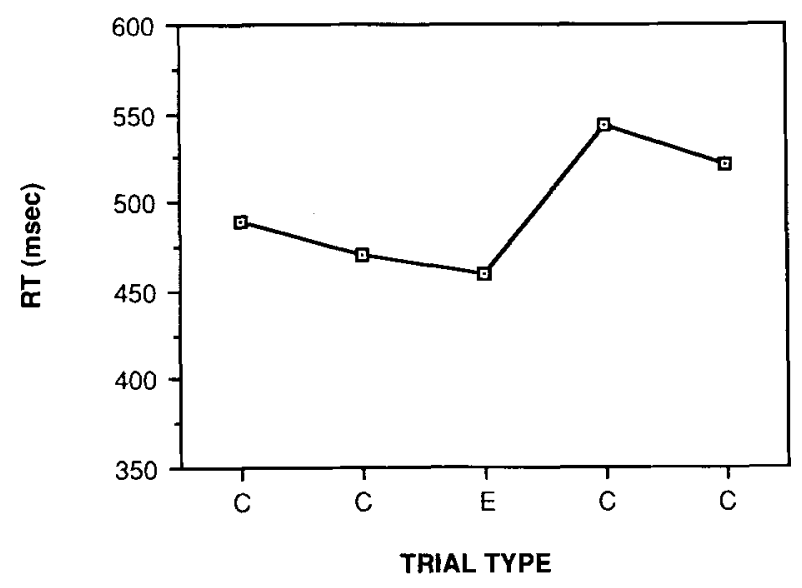

Figure 3. Mean response times for CCECC sequences (where the responses were not followed by a correction response or the "fast" key). $\mathrm{C}=$ correct response. $\mathbf{E}=$ error. 
The second analysis was conducted on CCFCC sequences $(\mathrm{C}=$ correct and $\mathrm{F}=$ correct and indicated as "fast"). The data from 5 subjects could not be included in the analysis as there were no CCFCC sequences in at least one of the two sessions. One subject has already been mentioned: in Session 1 he was unable to press the "fast" key in the time allowed. The remaining 4 subjects ( 2 in each group) indicated as "fast" over 100 trials (out of 200 ) in each session, and as a result produced no CCFCC sequences in at least one of the two sessions. Again a three-way analysis of variance was performed with group, session, and trial type (five levels: C, C, F, C, and C) as factors. There was no effect of group $[F(1,13)=2.65$, $p>.1]$ or session $[F(1,13)=1.18, p>.1]$, but there was a highly significant effect of trial type $[F(4,52)=$ $37.47, p<.01]$. There were interactions between group and session $[F(1,13)=7.44, p<.05]$ and between group and trial type $[F(4,52)=3.22, p<.05]$, and the interaction between session and trial type approached significance $[F(4,52)=2.29, p=.07]$. The three-way interaction was not significant $(F<1)$.

Figure 4 illustrates the overall trial type effect. Scheffé tests revealed that Trial Type 3 (F) was significantly different from all other trial types $(p<.01$ in every case) and that Trial Type 4 was significantly different from both Trial Types 1 and 5 ( $p s<.05$ ). The group $X$ session interaction again reflects a greater improvement across sessions for the NA/NA group ( $21 \mathrm{msec})$ than for the NA/A group ( $-49 \mathrm{msec}$ ), giving a very similar alcohol effect of $70 \mathrm{msec}$. The group $\times$ trial type interaction (which was marginally significant in the analysis of all the $\mathrm{CF}^{\prime}$ and CF response times) is simply further evidence that the two groups were not perfectly balanced in terms of the ability to indicate "fast" responses. Thus the difference between the mean of the four $\mathrm{C}$ trial types and the $F$ trial type was $116 \mathrm{msec}$ for the NA/NA group but $207 \mathrm{msec}$ for the NA/A group. Although the interaction between session and trial type did not quite reach significance in the present analysis of CCFCC sequences,

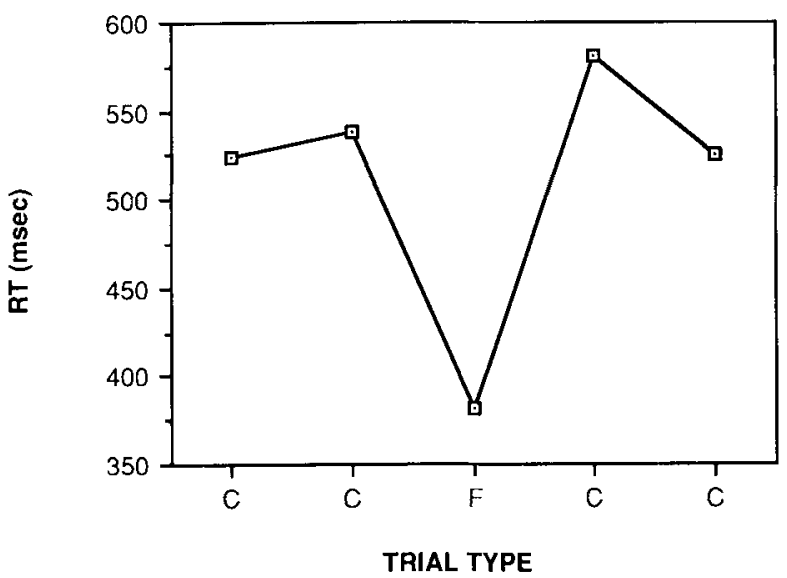

Figure 4. Mean response times for $\mathrm{CCFCC}$ sequences. $\mathrm{C}=$ correct. $\mathbf{F}=$ correct response indicated as "fast." the trend is similar to the significant effect found in the analysis of $\mathrm{CF}^{\prime}$ and $\mathrm{CF}$ response times. Thus, the difference between the mean of the four $\mathrm{C}$ trial types and the $F$ trial type increased from Session $1(137 \mathrm{msec})$ to Session 2 (186 msec). (In considering these last two interactions, it should be remembered that the analysis of the CCFCC sequences was based on fewer subjects and fewer responses per subject than the previous $\mathrm{CF}^{\prime} / \mathrm{CF}$ analysis. We should therefore place greater emphasis on the results from the analysis of $\mathrm{CF}^{\prime}$ and $\mathrm{CF}$ response times.)

To summarize what happens before and after a "fast" response, first, it is clear from Figure 4 that subjects do not gradually increase their speed until a particularly fast response is made and then indicate it by pressing the "fast" key. Instead, a "fast" response appears to come out of the blue, being on average $158 \mathrm{msec}$ faster than the previous response. The next correct response is rather slower than normal, although it is difficult to know whether this is simply a result of having to make an extra response (the "fast" key) during the RSI, or an actual adjustment in response criterion, similar to that following an error (see Figure 3).

Second, there is a tendency for the difference between the $\mathrm{F}$ trial type and the four $\mathrm{C}$ trial types immediately surrounding it to increase from Session 1 to Session 2. (Remember also that there was a significant interaction between session and response in the $\mathrm{CF}^{\prime} / \mathrm{CF}$ analysis.) We would argue from this that performance of the task of selecting "fast" responses improves with practice, since there was no difference between the two sessions in the proportion of responses indicated as fast.

We know from previous studies (e.g., Rabbitt \& Vyas, 1970) that practice decreases mean correct response time primarily because it reduces the size of the slow tail of the response time distribution. Consider the data from the NA/NA group: Because subjects performed the task after having received 2,324 choice response trials in the same session (see Procedure), they were already wellpracticed and thus the mean response time for all correct responses decreased by only $20 \mathrm{msec}$ from Session 1 to Session 2. We can safely assume that the decrease at the fast end of the response time distribution was even less than this. However, the decrease for CF responses across sessions for the NA/NA group was $41 \mathrm{msec}$. [It is worth noting that the results of an analysis of variance comparing all correct responses with CF responses, produced the same effects as that for $\mathrm{CF}^{\prime}$ and $\mathrm{CF}$ responses, including the highly significant interaction between session and response: $F(1,17)=9.78, p<.01$.] It is therefore extremely unlikely that the significant increase in the difference between $\mathrm{CF}^{\prime}$ and $\mathrm{CF}$ response times with practice (or the tendency for the difference between $\mathrm{Cs}$ and the $\mathrm{F}$ in the CCFCC sequences to increase with practice) can be attributed to an effect of practice on the number of fast responses available. Since the proportion of responses indicated as fast did not change with practice, and the response time distribution changed very little, it is proposed that the observed effects can be explained as 


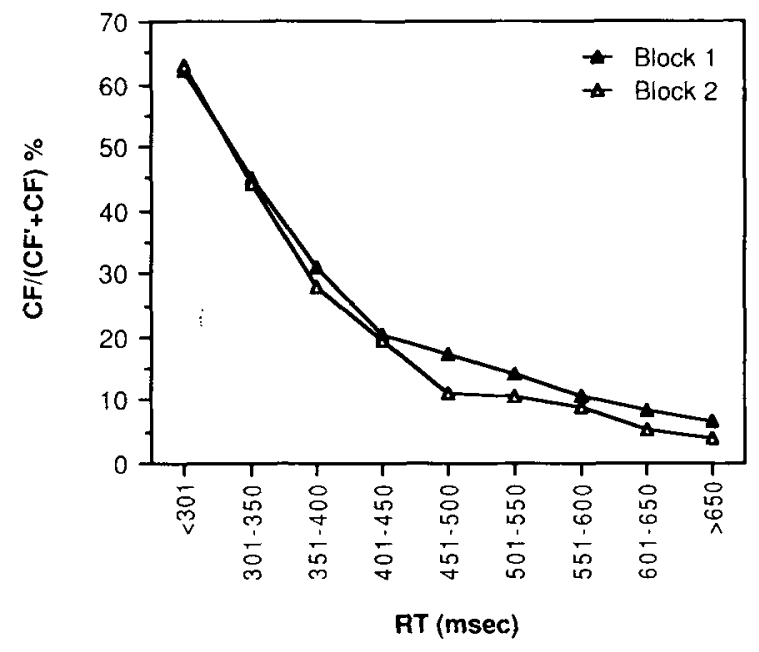

Figure 5. Results of additional study $(N=36$ ) showing the effect of practice on the slope of the function relating the number of correct responses indicated as "fast" (CF) as a percentage of the total number of correct responses $\left(\mathrm{CF}^{\prime}+\mathrm{CF}\right)$ for each of nine response time intervals: $\mathbf{4 0 0}$ trials per subject (200 in each block).

follows. In Session 1, subjects indicated some fast and some not-so-fast responses, whereas in Session 2 they indicated fast responses only. In other words, they "sharpened up" the distribution of responses indicated as "fast."

Because of computer problems, we were unable to plot for the present data the number of responses indicated as "fast" as a percentage of the total number of correct responses for several response time intervals, to examine whether or not the slope of the function became steeper with practice, as the above would suggest. Therefore, 38 new subjects were each given 100 practice trials of the four-choice reaction time task alone, prior to two blocks of 200 trials in which they were required to indicate fast and accurate responses as described earlier (see Procedure). Figure 5 summarizes the results. (The data from 2 subjects, who clearly misunderstood the instructions, were not included: One indicated no "fast" responses whatsoever, and the other indicated almost all responses as "fast.")

First, the subjects' ability to perform this task is clearly shown by the monotonic decrease in the probability of

Table 3

Further Analysis of Results from Additional Study: Numbers of CF' and CF Responses for Blocks 1 and 2 Less Than and More Than 450 msec

\begin{tabular}{ccc}
\hline Block & CF $^{\prime}$ & CF \\
\hline \multicolumn{3}{c}{ Responses $<450 \mathrm{msec}$} \\
2 & 1331 & 526 \\
& 1568 & 595 \\
& Responses $>450 \mathrm{msec}$ & \\
1 & 4359 & 576 \\
2 & 4236 & 395 \\
\hline
\end{tabular}

indicating a response as fast with increasing response time. Second, in agreement with the present conclusions, it does appear that the effect of practice is to reduce the probability that slow responses will be indicated as fast while not affecting the probability that fast responses will be indicated as fast. This was confirmed statistically by two chi-square tests on the numbers of $\mathrm{CF}^{\prime}$ and $\mathrm{CF}$ responses for Blocks 1 and 2 (see Table 3), first for responses less than $450 \mathrm{msec}\left[\chi^{2}(1)=.33, p>.05\right]$, and second for responses more than $450 \mathrm{msec}\left[\chi^{2}(1)=25.86\right.$, $p<.001]$. To summarize, practice affects the slope and this moves the intercept further to the left along the response time axis (see Figure 5).

Returning to the present study, there is no evidence that alcohol would have any adverse influence on the slope (although, as indicated above, we were unable to plot the complete functions). The presence of an overall alcohol effect and the absence of an interaction between alcohol and response (Figure 1) or trial type (Figure 4) together suggest that with alcohol, subjects are as efficient in distinguishing between fast and slow responses within a session as without alcohol. However, since all responses (correct, error, and "fast") are slower with alcohol, the intercept along the response time axis would be further to the right than without alcohol, both for the speed-error tradeoff function (see Maylor \& Rabbitt, 1987) and for the function described above.

\section{CONCLUSIONS}

First, it can be concluded that the two factors of interest, namely practice and alcohol, had significant effects on the overall rate of processing. Alcohol increased, and practice decreased, mean response times for all types of trial. Moreover, the effects did not interact with response type for CCECC sequences, which represent the limits of performance in terms of the tracking model outlined in the introduction (see also Maylor \& Rabbitt, 1989). Neither practice nor alcohol influenced the overall error rate. This is consistent with the results of Maylor et al. (1987), who argued that for tasks such as choice reaction time, in which subjects are aware of most of their errors, alcohol adversely affects speed but not accuracy (unless the dose is very high; see Maylor \& Rabbitt, 1987).

Second, it is clear that subjects were successful at the task of indicating fast and accurate responses. They were able to make a decision regarding each response within a third of a second. Approximately 1 in 4 correct responses were selected, compared with only 1 in 64 errors, demonstrating the ability to distinguish between accurate and inaccurate responses. The analysis of response times revealed that subjects were also highly efficient at distinguishing between fast and slow responses. Furthermore, responses indicated as "fast" were significantly faster than errors, which is perhaps surprising since errors in choice response tasks have been attributed to premature decisions based on insufficient evidence. Also, 
in contrast to errors, there appeared to be no warning (in the form of a gradual increase in speed) prior to a "fast" response.

The main question of interest was how this ability to judge response speed was affected by factors that affect rate of processing, namely practice and alcohol. There was a clear improvement with practice such that subjects initially indicated some fast and some not-so-fast responses, but then subsequently tightened up the response time distribution for "fast" responses by excluding slower responses. In contrast, alcohol did not impair the ability to judge response speed: $A$ All response times were significantly increased by the same amount (including the time to indicate a "fast" response, which was nonspeeded).

In terms of the control model described in the introduction, it is clear that the present dose of alcohol had no effect on subjects' ability to monitor the accuracy or speed of the response: subjects detected their errors both with and without alcohol and made an immediate adjustment to their response criterion following an error. They were also unimpaired by alcohol in their ability to monitor response speed, that is, to distinguish between fast and slow responses. However, the results do suggest that this latter aspect of control was improved by practice.

Rabbitt (1979b) compared choice response times from young and elderly subjects and similarly discussed the results in terms of the control process model. One possibility was that the elderly "simply cannot respond at the same rate as the young. That is, that all their responses are lagged by a constant relative to those of the young." This was rejected "since for particular categories of very fast responses (errors ...) both groups can respond in the same [response time] range" (p. 310; see also Rabbitt \& Goward, 1986). Although this simple lagging explanation fails to account for the effect of age, the present study suggests that it cannot be ruled out with respect to the effect of alcohol in speeded choice response tasks.

These results, together with those from Maylor and Rabbitt (1989), provide an interesting comparison between the effects of practice and alcohol on choice reaction time. Thus practice improves at least three things: (1) judgment of response speed (subjects learn to recognize slow responses), (2) rate of processing (subjects become faster at responding for the same number of errors), and (3) rate of preparation (subjects achieve optimal preparation in less time) (see Maylor \& Rabbitt, 1989). In contrast, alcohol impairs performance by slowing the rate of processing alone; that is, it has no adverse effect on either judgment of response speed or rate of preparation. At the very least, these conclusions illustrate the inadequacy of using mean reaction time and error rate only for describing performance in choice response tasks. For example, 2 subjects may have identical mean reaction times and error rates but differ in terms of rate of preparation and judgment of response speed, since one is sober but unpracticed and the other is drunk but practiced. Finally, it is interesting to speculate on the existence of some factor (a drug, stress, age, personality?) that would adversely affect all three aspects of performance discussed above, and then to test whether or not practice could completely compensate for the impairments observed.

\section{REFERENCES}

Jennings, J. R., Wood, C. C., \& LaWrence, B. E. (1976). Effects of graded doses of alcohol on speed-accuracy tradeoff in choice reaction time. Perception \& Psychophysics, 19, 85-91.

LAMING, D. (1968). Information theory of choice reaction times. London: Academic Press.

MAYLOR, E. A., \& RABbyTT, P. M. A. (1987). Effects of alcohol and practice on choice reaction time. Perception \& Psychophysics, 42, 465-475.

MaYLoR, E. A., \& RabBitT, P. M. A. (1989). Relationship between rate of preparation for, and processing of, an event requiring a choice response. Quarterly Journal of Experimental Psychology, 41A, 47-62.

Maylor, E. A., Rabbitt, P. M. A., Sahgal, A., \& Wright, C. (1987). Effects of alcohol on speed and accuracy in choice reaction time and visual search. Acta Psychologica, 65, 147-163.

RABBITT, P. M. A. (1966). Errors and error correction in choice-response tasks. Journal of Experimental Psychology, 71, 264-272.

RaBbitT, P. M. A. (1968). Three kinds of error-signalling responses in a serial choice task. Quarterly Journal of Experimental Psychology, 20, 179-188.

RabBitT, P. M. A. (1979a). Current paradigms and models in human information processing. In V. H. Hamilton \& D. M. Warburton (Eds.), Human stress and cognition: An information processing approach (pp. 115-140). New York: Wiley.

RABBITT, P. M. A. (1979b). How old and young subjects monitor and control responses for accuracy and speed. British Joumal of Psychology, 70, 305-311.

RabBiTt, P. M. A. (1980). A fresh look at changes in reaction times in old age. In E. Stein (Ed.), The psychobiology of aging: Problems and perspectives (pp. 425-442). Amsterdam: Elsevier North-Holland.

RABBITT, P. M. A., \& GowARD, L. (1986). Effects of age and raw IQ test scores on mean correct and mean error reaction times in serial choice tasks: A reply to Smith and Brewer. British Journal of Psychology, 77, 69-73.

RabbitT, P. M. A., \& Vyas, S. M. (1970). An elementary preliminary taxonomy for some errors in laboratory choice RT tasks. Acta Psychologica, 33, 56-76.

SANFord, A. J. (1970). Rating the speed of a simple reaction. Psychonomic Science, 21, 333-334.

Schouten, J. F., \& Bekker, J. A. M. (1967). Reaction time and accuracy. Acta Psychologica, 27, 143-153.

SHEPHERD, M. (1984). EMDISP: A visual display system with digital and analogue sampling. Behavior Research Methods, Instruments; \& Computers, 16, 297-302.

Wilkinson, R. T., \& Colquhoun, W. P. (1968). Interaction of alcohol with incentive and with sleep deprivation. Journal of Experimental Psychology, 76, 623-629.

(Manuscript received June 29, 1988; revision accepted for publication October 17,1988 .) 